\title{
The Selection and Improvement of China's Financial Regulatory Model under the Financial Crisis
}

\author{
Ai shuo ${ }^{1, a}$ \\ ${ }^{1}$ The property division, Shijiazhuang Vocational Technology Institute, Shijiazhuang, Hebei 050000, \\ China
}

a260002922@qq.com

Keywords: Financial Crisis ,Selection, Improvement, Financial Regulatory Mode, Chinese

\begin{abstract}
The global financial crisis triggered by US subprime mortgage crisis is a comprehensive test for national financial supervisory model. By analyzing the malpractice of US regulators pattern and US government' response to the crisis, we have found that in the prevention and control of financial risks and maintain financial security, strengthen financial regulation and financial innovation should go hand in hand. We also believe that a sound and efficient financial regulatory mechanism must be comprehensive coordinate with the legislative, administrative law enforcement and judicial. Despite China's current financial regulation model is essential for China's national conditions, but we still should reform and improve the situation based on reality and the future development.
\end{abstract}

\section{Introduction}

Although the final impact of the US subprime mortgage crisis triggered by the global financial crisis has not yet conclusive, but the financial crisis has exposed the world's major developed countries in particular, financial regulation of the United States, there are obvious flaws, the situation from the United States into crisis management its current reform ideas proposed point of view, which is to strengthen government regulation of the direction of change. US regulatory model for comprehensive sort, and to re-examine our regulatory model, we can clarify for our future financial regulatory reform and improve the relatively clear ideas [1].

\section{The US Financial Regulatory Model and Related Problems}

Reflection on this by the United States and the onset of the global financial crisis spread, many people have such a consensus: the US financial regulatory authorities for excessive financial innovation and securitization of financial markets arising from the real estate bubble there is a serious lack of supervision, many scholarsHe criticized the US government on the prevention and control of the financial crisis there is a clear problem of insufficient omission or as. Although this also points directly to the deep-seated reasons for the financial crisis, but also the need for the US financial regulatory philosophy, institutional and legal systems to further sort out the problems and reveal.

The regulatory philosophy: the neo-liberal values. With the emergence of the United States in the 1970s stagflation problem, to revive the traditional liberal ideals, and reduce government intervention in the economy and society as the main economic policy objectives of the new liberalism began to rise, and gradually become the dominant US economic policy and financial legislation mainstream value orientation, its main contents include reducing government intervention in the financial, labor and other markets, the lifting of strict financial controls, implemented to promote consumption, high-consumption-led high growth. A series of financial policies and legislation in the United States under the neoliberal theoretical guidance to take to alleviate since the 1970s, American economic decline, the consolidation of the US financial strong position in the world has played a crucial role. But it is precisely because of this practice and government regulation under the theoretical guidance of opposition, appears excessive financial innovation, in the absence of government regulation is not in place or circumstances, the behavior of market participants chase 
high returns over the lack of effective constraints, thereby lead to excessive risk, after several years of fermentation, financial risks under the new banner of liberalism ultimately detonated cover and shelter from the subprime mortgage crisis and then quickly evolved into a global financial crisis.

The regulatory regime: the "double bull" leads to regulatory inefficiencies and regulatory vacuum. In spite of US complex number of regulators agencies and regulators covering all the financial sector, but the quality is not proportional to the number of supervisory regulatory authorities. In the real context of the financial innovation continue to occur, and emerging regulatory vacuum, the overall efficiency of its highly regulated industry insiders questioned. From an empirical point of view, the current US regulatory model double bulls mainly the following two questions [2]:

First, a large number of regulatory bodies and poor coordination, affecting the efficiency of supervision. There must be adequate coordination to a single regulatory agency within their respective areas of regulatory compliance violations when individual has a good regulatory results, but these illegal violations in the field covered by the scope of supervision of individual institutions breakthrough, between the regulatory bodies resolve evolutionary behavior by individual risk out of the system. The reality is that cooperation between the regulatory bodies 115 significantly due to poor information or other reasons authorized by law not be achieved, or that / best opportunity often because of regulatory meetings and awaiting approval and fleeting.

Second, the regulatory segment resulting regulatory vacuum. Since Although the "Financial Services Act 1999" Since the enactment of the US regulatory system has been adjusted, but it did not shake the basic pattern of banking, insurance, securities separate supervision fundamentally, regulatory region of each regulatory body is still relatively isolated. Thus, among the various regulatory bodies to content regulation is not easy to achieve seamless.

The legal system: absence of government in risk control design. The United States is a country ruled by law, its financial regulatory system is through a set of legal system to build. Despite the financial risk control of financial regulation in the United States legal system a very important element, but we note that the relevant system design but in some of the key aspects of a missing unintentionally, specifically in the following areas [3]:

First, the law designed primarily focuses on the relationship between market participants to adjust the body between each other, they are often excluded from the role of government prevention mechanisms.

Secondly, in the asset securitization legislation, the law designed primarily around the main market of bankruptcy firewall settings between each other, does not solve the problem from the risk source such as sub-prime crisis on the emergence of a large number of securities underlying assets lax review, broad standard conditions. In the case of lack of supervision, the lenders in order to chase more profits in the competition, continued to relax lending conditions and expand the size of loans that financial risk is a steady stream produced and accumulated, eventually detonated the subprime crisis.

Finally, the regulation of credit rating agencies, long-term absence. Moody's, Standard \& Poor's, the benefits as the first credit rating agencies have been in the global financial market has a high voice, which to a large country as small as a product of the credit rating market have the ability to judge right and left, and in the sub-prime before the crisis, the rating agencies of the subordinated bonds is given a high credit rating, is tantamount to the entire financial market installed a time bomb. Credit rating agencies have been subject to market true why haste? The reason is not included in the long-term credit rating agency of the US government strictly regulated category. Although Enron let the American government realized the importance of the supervision of credit rating agencies, and in 2006 five credit rating agencies Reform Act of 6 for the first time established the US Securities and Exchange Commission (SEC) on credit rating agencies regulatory powers, but this one dimension of regulation is limited.

\section{The Choice of Financial Supervision Pattern}


Emerging market economies as China and the total GDP WTO member countries have open financial markets are listed fourth in the world, and in this financial crisis, the loss to be small compared with other developed countries in addition to China's Premier Wen Jiabao stressed that economic fundamentals outside good side factors, led to government regulation of Chinese-style financial supervision model also played a very strong role to resist. Although scholars of China are currently sub-sector regulatory model "a bank and three meetings" Pattern is reasonable, there are still a lot of controversies, but we believe that the current regulatory model is both a historical choice but also with the current status of China's financial sector basic adaptation [4].

Select financial supervision mode is actually two sides of a problem, not as either-or relationship appellation, but only focus of concern is different. Law Fundamentally, it is order, fairness, justice, freedom, security and efficiency of its timeless core values. No matter from what point of view, there is not fundamental conflict between these types of core values. From the above viewpoint, adhere to separate supervision commentators and critics advocate mixed supervision pursue different or that different focus in pursuit of the realization of the core values of the rule of law is the same, except that the basis for judgment. Considered reasonable sub-sector regulatory perspective is based on the reality of China's financial industry, that from a security point of view the financial sector; and that the mixed reasonable supervision view is based more on the development trend of the financial sector, improving the efficiency of the financial sector set off. In this sense, the two judgments are reasonable, are based on judgments made by objective reality. Therefore, we believe, confined to what model which better debate its real significance is not large, comprehensive study of China's financial supervision should go into further detail of the analysis made more operational significance of the conclusions. In the context of the current financial crisis, the Chinese Banking surviving a number of risks under the legislation is still inadequate level of supervision, supervision technology is not yet perfect, insist on separate supervision model is also reasonable and current situation of financial development The basic conditions adapt. We should be the core value of financial law as a guide, objective and realistic way for the shortcomings of the existing regulatory regime to make further carding under without substantial plugging radical change and improvement, while also based on empirical analysis and forecasting financial industry trends, carefully check for future legislation to improve the analysis and suggestions.

\section{The Reform and Perfection of Financial Supervision Pattern}

Strengthen the research of solving the problem of lagging behind financial law. Financial products and their variability and complexity of the transaction determine the financial regulation should continue to make adjustments to meet the objective needs of market development. The current financial legislation financial flexibility and regulatory requirements may often there is a gap. Legislation Although the reality status summary and confirmation, but often with time delays, while legal changes and because the repair method procedures are relatively complicated reasons, the existing law may be difficult to accurately reflect the situation in financial markets rapidly changing and timely response to the financial relationship between the adjustment needs. Therefore, strengthening the government regulation must address the problem of financial law is lagging behind, in order to ensure government regulation in the framework of the rule of law to run [5].

Timely promote the legal status of "Three Meetings" and strengthen its supervisory duties. In view of the financial occupies a very important position in a country's economy, government regulation of the financial sector which should be made to bear authoritative. The financial crisis has strengthened the authority of financial regulators and increase regulatory permissions become the realistic choice in some countries. We note that many of the country's financial regulator has a very high legal status, such as the US Securities and Exchange Commission (SEC) in the federal system of government, is not affiliated departments President, Congress and the Supreme Court, which has a high degree of independence and authority; major Japanese securities regulatory agency is the Ministry of Finance of the Securities Authority, a government administrative agency. But as our government regulatory agencies "a bank and three meetings", the People's Bank of China is the only 
government administrative bodies, while the other "three meetings" is included in the sequence of institutions directly under the State Council. Although the "three meetings" in accordance with laws and regulations and enjoyment of the State Council authorized administrative custody, charged with the responsibilities of national financial regulatory authorities, but the original meaning of the terms of institutions, the legal status of the State Council financial supervision institutions and their as yet not much match, the nature of its institutions and its administrative powers and administrative responsibilities have to assume it is difficult to withstand rigorous scrutiny of the law, thus inevitably affect their financial markets authority should have the authority. We believe that starting from strengthening government financial regulation, could be considered at an appropriate time to enhance the "Three Meetings" legal status, to change the nature of its institutions, administrative departments under the State Council as a sequence of independent functioning administrative bodies, which can only enhance its independence and authority, to attract high-quality personnel involved in financial regulation, more conducive to the strengthening of the role of government regulation, intensity and improve regulatory quality.

Construct and strengthen the coordinating mechanism adapting to government regulation in the legislative, judicial and administrative enforcement. Improve the efficiency of the financial regulatory system must rely on full cooperation of legislative, administrative and judicial enforcement. In the financial regulatory system configuration, government regulation is not the only factor, and strengthen government regulation will not solve all the problems of financial supervision, financial market trends, issues such as development also need to be resolved through legislation presets. While we emphasize the importance of government regulation, but history has proved that the development of financial markets, the public authority for this belongs to the category of civil and commercial affairs to intervene too much, it can lead to low efficiency of the market, therefore, to build a sound and efficient financial supervision system should also be under the premise of following the rule of law, strengthen coordination and cooperation of legislative, administrative and judicial enforcement.

\section{Conclusion}

The financial crisis not only provided the financial regulatory reform issues for United States but also for the countries around the world. Although China's financial regulatory system is essential for China's national conditions, but we still should summarize the lessons of our own practices, and thinking of reforming and improving based on the situation, the future development and the warning provided by financial crisis.

\section{References}

[1] Z. X. Cai, The financial liberalization and financial regulatory trends, J. Economic Problems. 44 (2010) 146-147.

[2] P.W, The legal issues in Wall Street financial crisis, J. Law. 18(2005) 55-57.

[3] P.Jiang, The economic crisis and the legal system, J. Gansu Social Science, 32(2012) 189-190.

[4] Z.X.Yang, The nature, causes and economic strategies of the current crisis, J, Law Forum, $4(2007) 38-40$.

[5] S.L.Zhu, The economic crisis and government regulation, J. Hunan Socialism Institute, 9(2013) 142-150. 